\title{
Immunoimaging of CXCR4 Expression in Brain Tumor Xenografts Using SPECT/CT
}

Sridhar Nimmagadda, Mrudula Pullambhatla, and Martin G. Pomper

Russell H. Morgan Department of Radiology and Radiological Sciences, Johns Hopkins University, Baltimore, Maryland

Chemokine receptor 4 (CXCR4) is expressed in a variety of cancers, including breast, brain, ovarian, and prostate. CXCR4CXCL12 interactions are critical for tumor development, growth, and metastasis. Compared with normal tissue, neoplastic tissue (including metastases) expresses high levels of CXCR4. Previous clinical and preclinical observations suggest that CXCR4 levels could be used as a predictive marker of metastatic potential. Here we report the results of SPECT/CT of CXCR4 expression levels in experimental brain tumors using ${ }^{125}$ I-labeled antiCXCR4 monoclonal antibodies (mAbs). Methods: hCXCR4 antibody $12 \mathrm{G} 5$ and control $\operatorname{lgG}_{2 \mathrm{~A}}$ antibody were radiolabeled. Radio-mAbs were obtained in $40 \%-60 \%$ yield, with $1.4-1.9$ $\mathrm{MBq} / \mu \mathrm{g}$ specific radioactivities and greater than $95 \%$ purity. Severe combined immunodeficient mice harboring U87 xenografts were used for ex vivo biodistribution and imaging studies. Surface CXCR4 expression levels on U87 tumor-derived cells were analyzed by flow cytometry. Results: Biodistribution and imaging studies showed a specific accumulation of ${ }^{125}$ I-12G5 in U87 tumors, with tumor-to-muscle uptake ratios reaching $15 \pm$ 3 at $48 \mathrm{~h}$ after injection. The tumor-to-tumor uptake ratio for ${ }^{125} \mathrm{~J}-12 \mathrm{G} 5$ and ${ }^{125} \mathrm{~J}-\mathrm{IgG}_{2 \mathrm{~A}}$ was 2.5 at $48 \mathrm{~h}$ after injection. Flow cytometry analysis of tumor-derived cells showed a 2- to 7-fold increase in CXCR4 expression relative to inoculums, accounting for the high mAb uptake observed in the tumors. Conclusion: Our data demonstrate the feasibility of imaging CXCR4 expression in experimental brain tumors. The elevated CXCR4 levels observed may have been, in part, due to the hypoxic tumor microenvironment.

Key Words: hypoxia; tumor microenvironment; molecular imaging; xenograft; chemokine

J Nucl Med 2009; 50:1124-1130

DOI: 10.2967/jnumed.108.061325

I

nteractions between chemokines and their receptors are emerging as an important group of mediators within the tumor microenvironment. Of the known chemokines, stromalderived factor 1 (SDF1), or CXCL12, and its receptor, chemokine receptor 4 (CXCR4), have gained attention because of their role in promoting cancer metastasis and stem cell homing and engraftment. CXCR4 expression has

Received Dec. 16, 2008; revision accepted Mar. 16, 2009.

For correspondence or reprints contact: Martin G. Pomper, Johns Hopkins Medical Institutions, 1550 Orleans St., 492 CRB II, Baltimore, MD 21231.

E-mail: mpomper@jhmi.edu

COPYRIGHT @ 2009 by the Society of Nuclear Medicine, Inc. also been proposed as a prognostic factor in several cancers, including brain, breast, colon, prostate, melanoma, and osteosarcoma (1).

Several brain tumor cell lines, primary tumors, and metastases, compared with normal brain parenchyma, demonstrate high concentrations of CXCR4 receptors $(2,3)$. CXCR4 levels were elevated with respect to tumor grade, demonstrating the highest levels in grade IV tumors (glioblastomas) (2). Rempel et al. showed that the CXCR4CXCL12 axis modulates vascular endothelial growth factor expression and angiogenesis and the immune response (2). Low-molecular-weight inhibitors targeting CXCR4 not only inhibit the growth of primary brain tumors but also synergize with standard, cytotoxic chemotherapy $(4,5)$. Those observations suggest that CXCR 4 could be an important target for the imaging of primary tumors and metastases within the neuraxis, possibly providing important prognostic information, or for the monitoring of therapies.

Recent improvements in diagnostic imaging have enabled the early detection and management of cancer (6). For example, mammograms are the current clinical mainstay of breast cancer imaging, serving as an example of a successful image-based screening test for cancer. MRI is frequently used to delineate the extent of disease in breast, central nervous system, and other cancers (7). Highly sensitive functional imaging techniques such as PET with ${ }^{18}$ F-FDG, for glucose metabolism, and ${ }^{18} \mathrm{~F}$-fluorothymidine, for tumor proliferation, are used for the diagnosis, staging, and therapeutic monitoring of cancer $(8,9)$. However, these metabolic imaging techniques cannot detect specific receptor expression in the tumor (i.e., estrogen receptor, human epidermal growth factor receptor type 2 [HER2], or CXCR4, which have important prognostic implications) $(10,11)$. Noninvasive imaging studies of estrogen receptor and HER 2 expression by nuclear imaging techniques are under way (12-14). Of these receptors, only CXCR4 is directly involved in the metastatic process and is a well-characterized biomarker for the direct imaging of tumor metastatic potential (15-17).

Because of their target-binding specificity, monoclonal antibodies (mAbs) provide an attractive choice as a molecular scaffold for radiopharmaceutical-based imaging. That potential has largely gone unrealized because of the relatively poor pharmacokinetic properties of mAbs, such as long circulation time and large size, mitigating solid tumor 
penetration. However, radiolabeled mAbs generated recently are providing viable clinical imaging agents (18). Because of the importance of CXCR4 in brain tumor development, growth, and metastasis, we generated a radiolabeled version of a mouse antihuman CXCR4 antibody (12G5) (19) and used it to evaluate CXCR4 expression in U87 human glioblastoma xenografts with SPECT.

\section{MATERIALS AND METHODS}

\section{Cell Lines}

The human glioblastoma cell line U87 was purchased from American Type Culture Collection and maintained in Dulbecco's modified Eagle's medium (DMEM) supplemented with $10 \%$ fetal bovine serum, $100 \mathrm{U}$ of penicillin per milliliter, and $100 \mathrm{mg}$ of streptomycin per milliliter. A U87 cell line stably transfected with human CD4 and CXCR4 (U87-stb-CXCR4) was obtained from the National Institutes of Health AIDS Research and Reference Reagent Program. The U87-stb-CXCR4 cell line was maintained in DMEM supplemented with $15 \%$ fetal bovine serum, $1 \mu \mathrm{g}$ of puromycin per milliliter, $300 \mu \mathrm{g}$ of G418 per milliliter, $100 \mathrm{U}$ of penicillin per milliliter, and $100 \mathrm{mg}$ of streptomycin per milliliter. Both the cell lines were maintained in a humidified incubator with $5 \% \mathrm{CO}_{2}$. All cell culture reagents (Gibco) were purchased from Invitrogen.

\section{Antibody Radiolabeling}

The mouse antihuman CXCR4 antibody (clone 12G5) was obtained from the National Institutes of Health AIDS Research and Reference Reagent Program and also purchased from R\&D systems, Inc. (cat. no. MAB170). Isotype-matched control mouse $\mathrm{IgG}_{2 \mathrm{~A}}$ antibody was purchased from $\mathrm{R} \& \mathrm{D}$ systems, Inc. (clone 20102, cat. no. IC003P). ${ }^{125} \mathrm{I}$-sodium iodide ( $\left.{ }^{125} \mathrm{I}-\mathrm{NaI}\right)$ was purchased from MP Biomedicals. Antibodies were labeled using a modified version of the IODO-GEN method (Pierce) (1). Briefly, $37-74 \mathrm{MBq}(1-2 \mathrm{mCi})$ of ${ }^{125} \mathrm{I}-\mathrm{NaI}$ were incubated with $25 \mu \mathrm{g}$ of purified antibody in 50-100 $\mu \mathrm{L}$ of phosphate-buffered saline (PBS) in an IODO-GEN-coated reaction vial. Reaction times varied between 5 and $10 \mathrm{~min}$. Radiolabeled antibody was purified from low-molecular-weight impurities using size-exclusion chromatography on a Sephadex G-25 desalting column (Amersham Biosciences) preconditioned with PBS ( $\mathrm{pH}$ 7.4). Protein purities were determined by instant thin-layer chromatography.

\section{Receptor Binding Assays}

U87 and U87-stb-CXCR4 cells seeded in 6-well plates at 60\%$80 \%$ confluence were used for receptor binding assays. Cells were incubated with $37 \mathrm{kBq}(1 \mu \mathrm{Ci}) / \mathrm{mL}$ of either ${ }^{125} \mathrm{I}-\mathrm{IgG}_{2 \mathrm{~A}}$ or ${ }^{125} \mathrm{I}-12 \mathrm{G} 5$ in PBS supplemented with $0.5 \%$ bovine serum albumin and $2 \mathrm{mM}$ ethylenediaminetetraacetic acid for 30 and $60 \mathrm{~min}$ at $4^{\circ} \mathrm{C}$. After incubation, cells were washed quickly 4 times with $4^{\circ} \mathrm{C}$ binding buffer and trypsinized using nonenzymatic buffer; cell-associated activity was determined in a $\gamma$-spectrometer (1282 Compugamma CS; Pharmacia/LKB Nuclear, Inc.). Radioactivity values were converted into percentage of incubated dose per microgram of total protein. Experiments were performed in triplicate and repeated 3 times. Immunoreactive fraction of ${ }^{125} \mathrm{I}-12 \mathrm{G} 5$ was determined using U87-stb-CXCR4 cells as described previously (20). Data were fitted according to linear regression analysis using PRIZM software (GraphPad Software, Inc.), and the extrapolation to the ordinate was used to calculate the immunoreactive fraction.

\section{Animal Models}

Male BALB/C severe combined immunodeficient mice (age, 6-8 wk; weight, between 25 and $30 \mathrm{~g}$ ) were purchased from the National Cancer Institute. All of the experimental procedures using the animals were conducted according to protocols approved by the Johns Hopkins Animal Care and Use Committee. Mice were implanted subcutaneously with U87 cells $\left(4 \times 10^{6}\right.$ cells $\left./ 100 \mu \mathrm{L}\right)$ in the right upper flank. After 2-3 wk, when the tumor size was 600$800 \mathrm{~mm}^{3}$, the animals were used for biodistribution and SPECT/CT experiments.

\section{SPECT/CT}

An X-SPECT small-animal SPECT/CT system (Gamma Medica-Ideas) was used for image acquisition. Three mice for each radiolabeled antibody were used for imaging studies. After an intravenous injection of $37 \mathrm{MBq}(1 \mathrm{mCi})$ of radiolabeled antibody, images were acquired at 24,48 , and $72 \mathrm{~h}$ after injection. The SPECT projection data were acquired using 2 low-energy, high-resolution parallel-hole collimators with a radius of rotation of $4.65 \mathrm{~cm}$ (spatial resolution, $1.6 \mathrm{~mm}$ ). The tomographic data were acquired in 64 projections over $360^{\circ}$ at $40 \mathrm{~s}$ per projection. After tomography, CT was acquired in 512 projections to allow anatomic coregistration. Data were reconstructed using the ordered subsets-expectation maximization algorithm and analyzed using AMIDE software (free software provided by SourceForge). Maximum-intensity-projection images were generated using Amira 5.2.0 software (Visage Imaging Inc.).

\section{Ex Vivo Biodistribution}

Animals were injected with $74 \mathrm{kBq}(2 \mu \mathrm{Ci})$ of either ${ }^{125} \mathrm{I}-\mathrm{IgG}_{2 \mathrm{~A}}$ or ${ }^{125} \mathrm{I}-12 \mathrm{G} 5$ in $200 \mu \mathrm{L}$ of saline via the tail vein. At $24,48,72,96$, and $120 \mathrm{~h}$ after injection, blood, lung, muscle, heart, spleen, stomach, small intestine, kidney, liver, and tumor samples were collected and weighed, and their radioactivity content was determined in an automated $\gamma$-spectrometer. Aliquots of the injected tracer and tumor samples were counted and served as standards for the calculation of the percentage injected dose per gram of tissue. Three animals per time point were used. Ratios of ${ }^{125} \mathrm{I}-12 \mathrm{G} 5$ uptake to control ${ }^{125} \mathrm{I}-\mathrm{IgG}_{2 \mathrm{~A}}$ antibody uptake and ratios of tumor to muscle and tumor to blood were calculated. One set of mice with a tumor size less than $200 \mathrm{~mm}^{3}$ was also used for biodistribution studies.

\section{Tumor Cell Extraction and Flow Cytometry}

Tumors from an additional group of 5 mice were extracted, and CXCR4 expression levels were analyzed by flow cytometry and immunoblot analysis. Briefly, U87 tumors were cut into multiple small cubes and dissociated at $37^{\circ} \mathrm{C}$ for $30 \mathrm{~min}$ with $0.5 \mathrm{mg}$ of collagenase II per milliliter in DMEM medium. The cell suspension was filtered through a cell strainer with 70- $\mu$ m nylon mesh (Becton Dickinson Biosciences). The dissociation procedure was repeated 3 times to maximize the cell yield. Cells collected by centrifugation were washed 3 times with DMEM fortified with $10 \%$ fetal bovine serum and cultured in DMEM as described above. The tumorextracted cells were seeded at $2 \times 10^{6}$ cells $/ \mathrm{mL}$ in $100 \mathrm{~mm}$ plates and used for flow cytometry analysis after 1 or 2 passages. At $50 \%-70 \%$ confluence, cells were washed twice with PBS buffer and plates were placed on ice to prevent receptor internalization. Cells were detached using a nonenzymatic cocktail (cat. no. C5914; Sigma). To induce hypoxic conditions in vitro, U87 cells were incubated with a hypoxia mimetic $(0.1 \mathrm{mM}$ cobalt chloride) for $48 \mathrm{~h}$ before processing. The expression levels of CXCR4 in the normoxic and hypoxic conditions were determined by immunostaining with CXCR4 12G5 
mAb conjugated to phycoerythrin (cat. no. FAB170P; R\&D Systems) according to the manufacturer's instructions. Cells were analyzed for CXCR4 expression on a flow cytometer (FACSCalibur; BD Biosciences). Ten thousand events were acquired in list mode, and data were analyzed using Cellquest software (Becton Dickinson).

\section{Protein Lysates and Immunoblot Analysis}

U87 and tumor-derived U87 (U87-TMD) cells in $100 \mathrm{~mm}$ plates were washed twice with PBS and homogenized with Tris-lysis buffer (100 mM Tris [pH 6.7], 2\% sodium dodecylsulfate, and $12 \%$ glycerol) containing protease inhibitor cocktail (Sigma). Protein concentrations were determined using a Bio-Rad protein assay kit (Bio-Rad Laboratories). Standard concentrations of bovine serum albumin were used to obtain a calibration curve. Aliquots containing $50 \mu \mathrm{g}$ of the total protein and with a molecular weight standard were loaded and electrophoretically separated on a $10 \%$ polyacrylamide gel. Separated proteins were transferred onto nitrocellulose membranes and blocked with $5 \%$ nonfat milk with $0.05 \%$ polysorbate- 20 for $1 \mathrm{~h}$ at room temperature. Membranes were then incubated with the rabbit anti-CXCR4 polyclonal antibody (1:500 dilution) raised against a peptide corresponding to amino acids 1-14 of human CXCR4 (ProSci Inc.), followed by mouse antirabbit secondary antibody conjugated to horseradish peroxidase (1:2,500 dilution). After 3 washes, bands were visualized using the Supersignal West Pico chemiluminescent substrate kit (Pierce Biotechnology Inc.). $\beta$-Actin served as a control.

\section{Data Analysis}

Statistical analysis was performed using an unpaired 2-tailed $t$ test. $P$ values of less than 0.05 for the comparison between CXCR4specific and control antibody uptake were considered to be statistically significant.

\section{RESULTS}

\section{Antibody Radiolabeling}

Yields for radioiodination were typically 40\%-60\%, with purities greater than $95 \%$. Specific radioactivities of the iodinated antibody were 1.85 and $1.48 \mathrm{MBq} / \mu \mathrm{g}$ for ${ }^{125} \mathrm{I}-$ $12 \mathrm{G} 5$ and ${ }^{125} \mathrm{I}-\mathrm{IgG}_{2 \mathrm{~A}}$, respectively.

\section{Antibody Specificity}

As demonstrated in Figure 1, ${ }^{125} \mathrm{I}-12 \mathrm{G} 5$ showed greater than $98 \%$ specificity toward U87-stb-CXCR4 cells. The levels of ${ }^{125} \mathrm{I}-12 \mathrm{G} 5$ binding to U87 were similar to but significantly different $(P=0.04)$ from those of the control ${ }^{125} \mathrm{I}-\mathrm{IgG}_{2 \mathrm{~A}}$ antibody. These results were in agreement with the low surface CXCR4 expression levels observed in U87 cells with flow cytometry (Figs. 1 and 2). The immunoreactive fraction of the radiolabeled antibody was 0.87 , as indicated in Figure 1B.

\section{SPECT/CT}

SPECT/CT of U87 tumors with ${ }^{125} \mathrm{I}-12 \mathrm{G} 5$ demonstrated a clear and specific accumulation of radioactivity in the U87 tumors by $24 \mathrm{~h}$, and the radioactivity was slowly clearing by $72 \mathrm{~h}$ (Fig. 3A). The tumor-to-nontumor contrast was maximum at $48 \mathrm{~h}$ after injection. The control ${ }^{125} \mathrm{I}-\mathrm{IgG}_{2 \mathrm{~A}}$ antibody also showed accumulation of radioactivity, although less than ${ }^{125} \mathrm{I}-12 \mathrm{G} 5$ (Fig. 3B). A maximum-intensity projection of ${ }^{125} \mathrm{I}-12 \mathrm{G} 5$ showed highest uptake in the spleen (Fig. 3C).

\section{Ex Vivo Biodistribution}

To quantify the degree of radiopharmaceutical uptake on a per-organ basis, U87 tumor-bearing animals were injected with either ${ }^{125} \mathrm{I}-12 \mathrm{G} 5$ or ${ }^{125} \mathrm{I}-\mathrm{IgG}_{2 \mathrm{~A}}$ antibody and were followed for $5 \mathrm{~d}$. Figure 4 shows the combined experiments with both antibodies at 24,48 , and $72 \mathrm{~h}$ after injection. The animals injected with ${ }^{125} \mathrm{I}-12 \mathrm{G} 5$ showed consistently higher tumor uptake than did the animals that received ${ }^{125} \mathrm{I}-\mathrm{IgG}_{2 \mathrm{~A}}$. The ${ }^{125} \mathrm{I}-12 \mathrm{G} 5-$ to- ${ }^{125} \mathrm{I}_{-} \mathrm{IgG}_{2 \mathrm{~A}}$ ratios were $2.1,2.5$, and 1.7 at 24,48 , and $72 \mathrm{~h}$, respectively, after injection. In the case of ${ }^{125} \mathrm{I}-12 \mathrm{G} 5$ antibody, the amount of radioactivity increased in tumors until $48 \mathrm{~h}$ and then decreased; in normal organs, the radioactivity decreased with time after $24 \mathrm{~h}$. The ${ }^{125} \mathrm{I}-\mathrm{IgG}_{2 \mathrm{~A}}$ antibody showed a monotonic decrease in radioactivity both in tumors and in normal organs. The tissue-to-muscle ratios of ${ }^{125} \mathrm{I}-12 \mathrm{G} 5$ reached a maximum at $48 \mathrm{~h}$ after injection, but those of ${ }^{125} \mathrm{I}_{-} \mathrm{IgG}_{2 \mathrm{~A}}$ remained uniform until $72 \mathrm{~h}$ (Fig. 5).
FIGURE 1. 125 |-12G5 binding specificity to CXCR4. U87 and U87-stb-CXCR4 cells at $60 \%-70 \%$ confluency in 6-well plates were incubated with $37 \mathrm{kBq} / \mathrm{mL}$ $\left(1 \mu \mathrm{Ci} / \mathrm{mL}\right.$ ) of $\mathrm{mAbs}$ at $4^{\circ} \mathrm{C}$ for 30 (clear bars) and 60 (solid bars) min. Data are represented as percentage of incubated dose per microgram $(\% \mathrm{ID} / \mu \mathrm{g})$ of protein and represent mean values of 3 experiments \pm SEM (A). Comparative reference is control cell line for respective $\mathrm{mAb}$. (B) Immunoreactivity plot of 125 $12 \mathrm{G} 5$ for U87-stb-CXCR4 cells. ${ }^{*} P<$ 0.05. ${ }^{\star \star} P<0.01$. ${ }^{\star \star \star} P<0.001$. IF $=$ immunoreactive fraction.

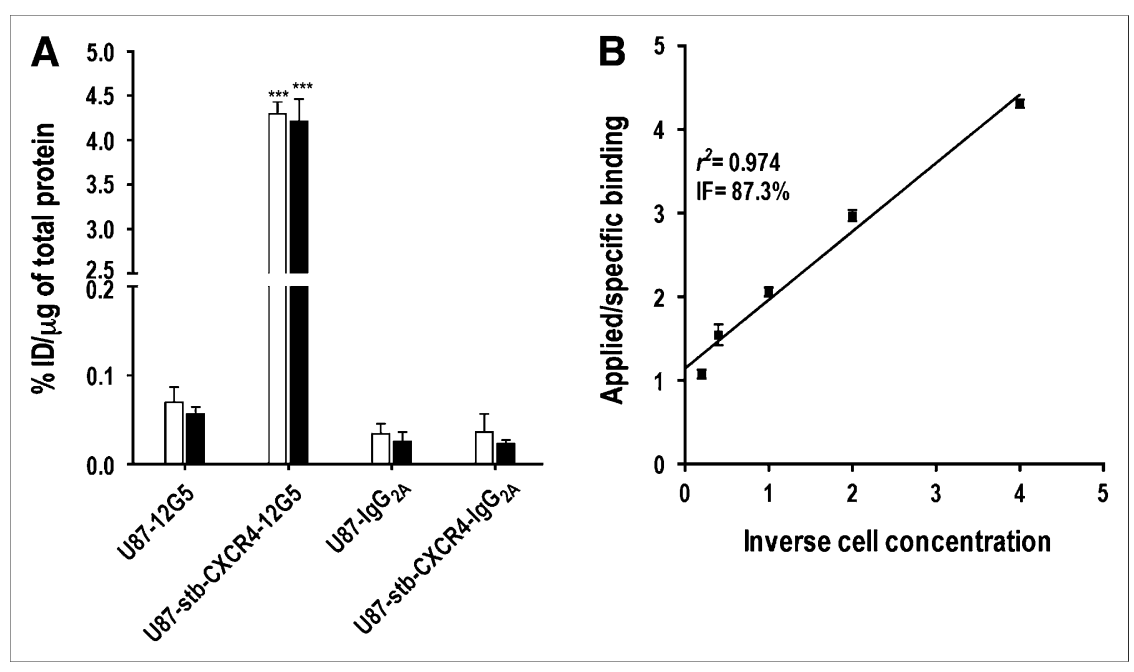




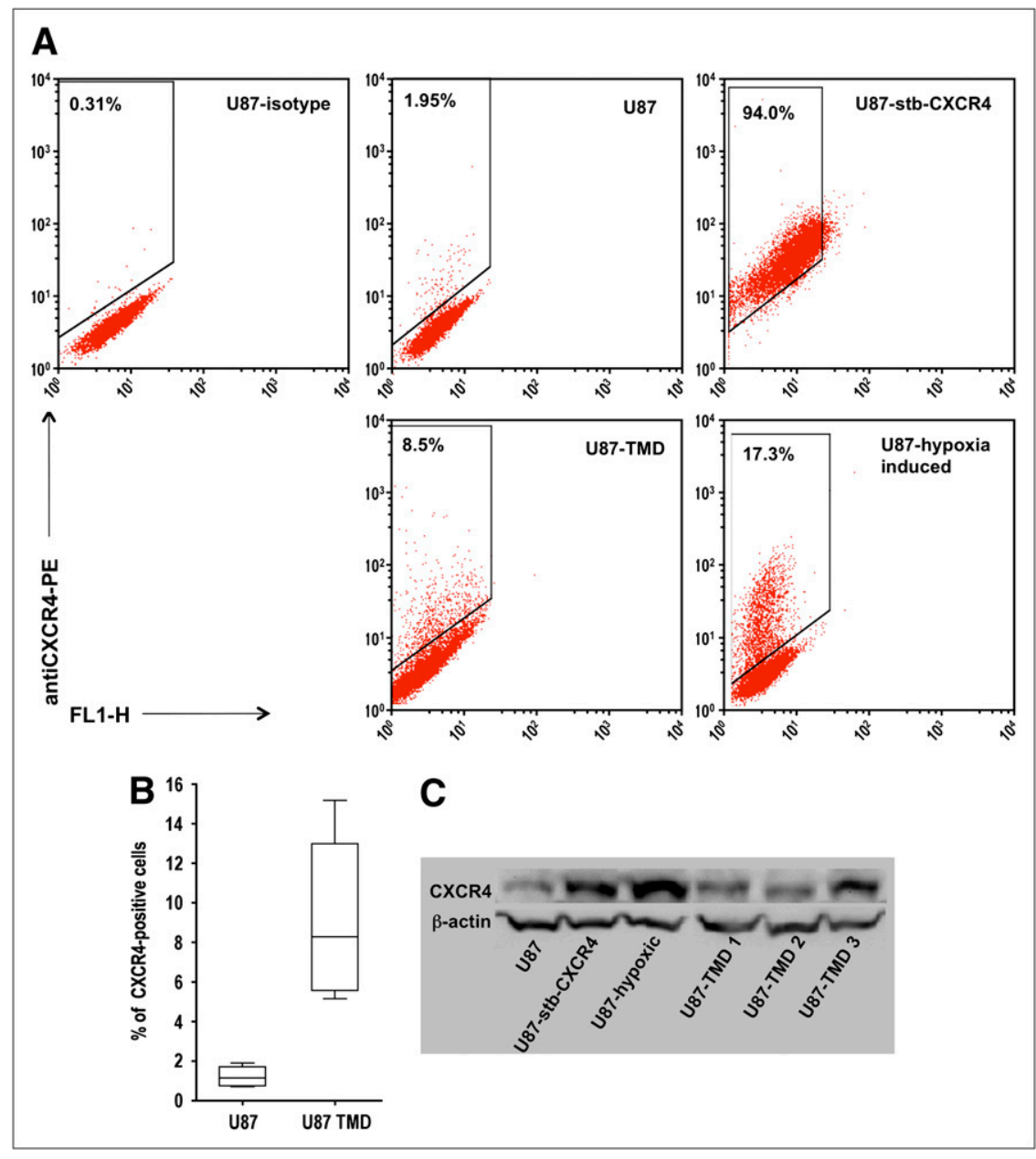

FIGURE 2. Flow cytometry and immunoblot analysis of CXCR4 expression. (A) U87 cells stained with matched isotype control $\lg _{2 A}-P E$ and $U 87$; U87-stb-CXCR4 representative U87TMD and U87-hypoxia-induced cell lines stained with 12G5-PE were analyzed on a BD FACScan instrument. Whisker graph showing the CXCR4 levels in U87-TMD cells. U87 cells from different passages were used as control (B). Immunoblot analysis of CXCR4 expression in U87, U87-hypoxic, and U87TMD cells (C).

Both radiolabeled antibodies demonstrated uniform uptake in all nontumor organs. Rapid clearance of radioactivity from the blood was observed, perhaps because of deiodination of the antibody. The spleen had the highest accumulation of radioactivity at all times.

\section{Flow Cytometry of Tumor-Derived Cells and Immunoblotting}

To assess the percentage of CXCR4-positive cells within the tumors, cells were extracted and analyzed by flow cytometry after 1 or 2 passages. The tumor-derived cells showed a 2- to 7-fold increase in surface CXCR4 expression levels (Figs. 2A-2C). Because most of the radioactivity observed was within the center of the tumors, we were prompted to investigate further the origin of this result. Because CXCR4 is known to have a hypoxia-responsive element in the promoter region (21), we suspected that hypoxic upregulation of CXCR4 expression occurred within the tumors and was more pronounced near the core of the tumors, in which oxygen tension was expected to be lowest (22). U87 cells maintained under hypoxic conditions showed an increase in CXCR4 levels, suggesting the role of hypoxia in driving CXCR4 expression. The total protein expression levels also indicated a similar pattern (Fig. 2C).

\section{DISCUSSION}

To monitor CXCR4 expression noninvasively, we radioiodinated and evaluated a CXCR4 $\mathrm{mAb}$ in mice harboring subcutaneous U87 brain tumor xenografts using SPECT/CT. We also associated the observed tumor uptake and retention of radioactivity with the surface and total CXCR4 protein expression levels that may have been upregulated by clonal expansion of high CXCR4-expressing cells.

As mentioned at the outset, CXCR4 expression has been proposed as a prognostic marker in several cancers (1). In addition, metastases often have elevated levels of CXCR4 expression $(17,23)$. Therefore, imaging agents for the noninvasive detection of CXCR4 would be beneficial not only for the assessment of metastatic potential of the primary tumor but also for the detection of systemic metastases. CXCR4 is expressed in several organs including the spleen, thymus, lung, and bone marrow; therefore, therapeutic agents targeting CXCR4 may result in unwanted toxicity (24). Imaging patients before therapy with a CXCR4-based imaging agent may enable avoidance of toxicity through quantification of normal organ radiopharmaceutical distribution.

Noninvasive detection of CXCR4 levels could be achieved using suitably functionalized, specifically targeted lowmolecular-weight agents or mAbs. To our knowledge, there 


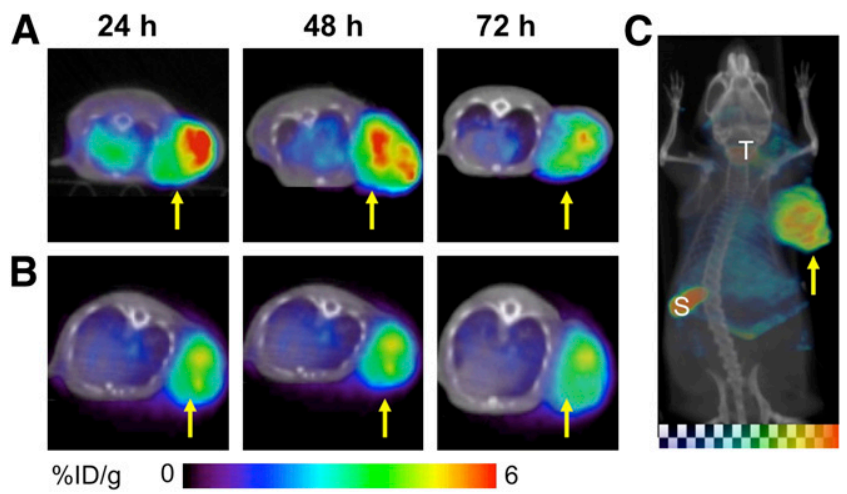

FIGURE 3. SPECT/CT of CXCR4 expression in subcutaneous U87 xenografts with mAbs. Severe combined immunodeficient mice bearing U87 glioblastoma xenografts were injected with $37 \mathrm{MBq}(1 \mathrm{mCi})$ of either ${ }^{125} \mathrm{I}-12 \mathrm{G} 5(\mathrm{~A})$ or ${ }^{125} \mathrm{I}$ $\operatorname{lgG}_{2 A}(B)$ via tail vein. SPECT/CT images were acquired at 24,48 , and $72 \mathrm{~h}$ after injection of mAbs. All images were adjusted to same maximum value to show relative active concentrations of tracers. Arrow depicts tumor in coronal sections. (C) Maximum-intensity-projection image of ${ }^{125} \mathrm{I}-$ 12G5-injected mouse at $48 \mathrm{~h}$ after injection; arrow shows tumor. $\% \mathrm{ID} / \mathrm{g}=$ percentage of injected dose per gram of tissue; $\mathrm{S}=$ spleen; $\mathrm{T}=$ thyroid.

has been only 1 reported attempt to image CXCR 4 expression in cancer using nuclear imaging techniques. Hanaoka et al. developed and evaluated ${ }^{111}$ In-labeled diethylenetriaminepentaacetic acid-Ac-TZ14011, a peptide analog of CXCL12. The authors found that conjugation with diethylenetriaminepentaacetic acid and labeling with ${ }^{111} \mathrm{In}$ reduced the specificity of the analog to CXCR4 by 6 -fold (25). To investigate the feasibility of CXCR4-based imaging, we radiolabeled a well-characterized CXCR4 antibody, 12G5, with ${ }^{125} \mathrm{I}-\mathrm{NaI}$. 12G5 recognizes a determinant in the first and second extracellular loops of CXCR4, and its specificity to CXCR4 is well established (26). Direct antibody radiolabeling with the IODO-GEN method did not impair the specificity of ${ }^{125} \mathrm{I}-12 \mathrm{G} 5$ antibody to CXCR4, as indicated by the in vitro binding studies. Imaging and biodistribution studies demonstrated a significant uptake of ${ }^{125} \mathrm{I}-12 \mathrm{G} 5$ in the U87 tumors, despite some nonspecific uptake observed with the ${ }^{125} \mathrm{I}-\mathrm{IgG}_{2 \mathrm{~A}}$ antibody. The uptake observed by the control antibody suggests that at least a portion of the uptake seen by ${ }^{125} \mathrm{I}-12 \mathrm{G} 5$ was also not due to receptor-mediated binding but rather to the enhanced permeability and retention effect commonly observed with macromolecular agents (27). The highest uptake of the radiolabeled mAbs was seen in the spleen, followed by the tumor. Similar nonspecific uptake of mAbs in the liver and spleen has been observed because of cross-reactivity with antigen-positive circulating cells and normal B cells in the blood or spleen and nonantigenic binding of antibody, such as Fc binding $(28,29)$. Methods based on predosing strategies $(30,31)$ to reduce nonspecific uptake have been developed; these methods could be applied in future studies.

The $\mathrm{mAb}$ used in this study is known to recognize only certain conformations of CXCR4 receptor $(26,32)$. Consequently, it is possible that we are underestimating the actual concentration of CXCR 4 expression on the cell surface, which may vary between cell types. If they could be generated, other radiolabeled antibodies that detect all conformations of CXCR4 may improve the specificity of radioimmunoimaging of CXCR4 and may also lower the nonspecific binding observed (32).

Biodistribution studies with small tumors $\left(<200 \mathrm{~mm}^{3}\right)$ showed no significant difference between the ${ }^{125} \mathrm{I}-12 \mathrm{G} 5$ and the ${ }^{125} \mathrm{I}-\mathrm{IgG}_{2 \mathrm{~A}}$ uptake at $48 \mathrm{~h}$ after injection $(P=0.08)$. To investigate further whether the significant retention $(P=$ $0.009)$ of radioactivity observed in larger tumors $(600-800$ $\mathrm{mm}^{3}$ ) was due to ${ }^{125} \mathrm{I}-12 \mathrm{G} 5$ binding to CXCR4 and not merely enhanced permeability and retention, we extracted the tumor cells and analyzed for surface CXCR4 expression by flow cytometry after 1 or 2 passages. The tumor-derived cells showed a 2- to 7-fold increase in surface CXCR4 expression. On the basis of the literature evidence, we postulated that the increased CXCR4 expression was due either to tumor hypoxia or to clonal selection of high CXCR4-expressing cells. U87 cells grown under conditions

FIGURE 4. Ex vivo biodistribution data for mAbs in tumor-bearing severe combined immunodeficient (SCID) mice. SCID mice harboring U87 glioblastoma xenografts were injected with $74 \mathrm{kBq}(2$ $\mu \mathrm{Ci})$ of either ${ }^{125} \mathrm{I}-12 \mathrm{G} 5$ or ${ }^{125} \mathrm{I}-\mathrm{IgG}_{2 \mathrm{~A}}$ via tail vein. At 24,48 , and $72 \mathrm{~h}$ after injection, selected tissues and tumors were harvested and weighed, and radioactivity was counted in a $\gamma$-spectrometer. All values were converted into percentage of injected dose per gram of tissue $(\% / D / g)$. Data are means \pm SEM of 3 animals. Comparative reference is ${ }^{125} \mid-\operatorname{lgG}_{2 \mathrm{~A}}$ uptake. ${ }^{*} P<0.05 .{ }^{\star \star} P<$ 0.01. ${ }^{\star \star \star} P<0.001$.

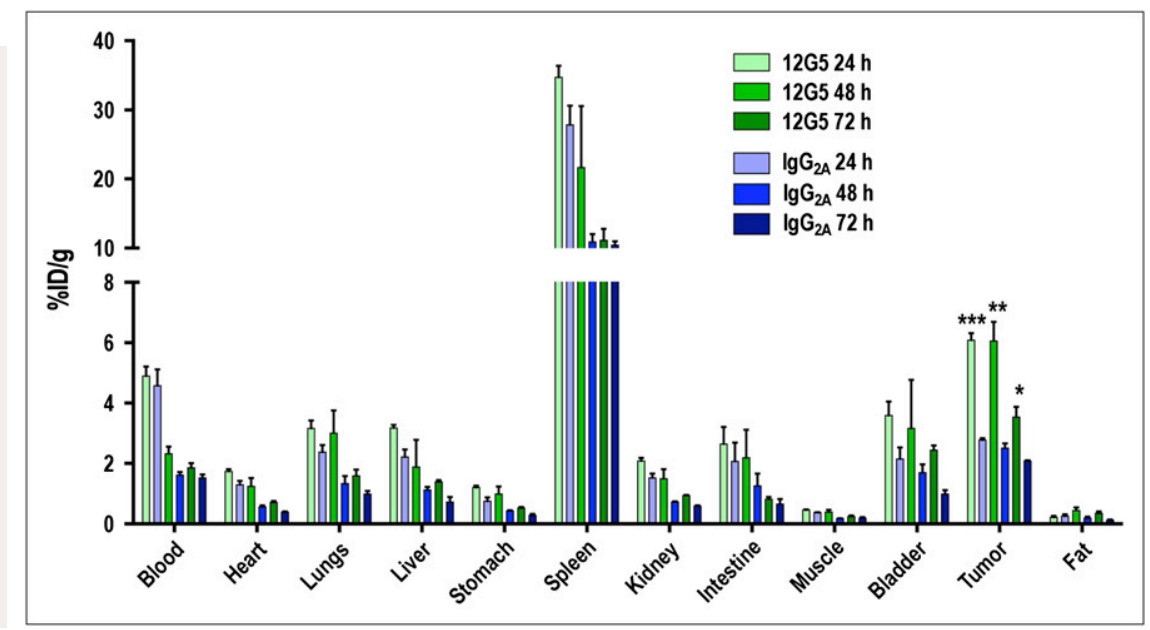




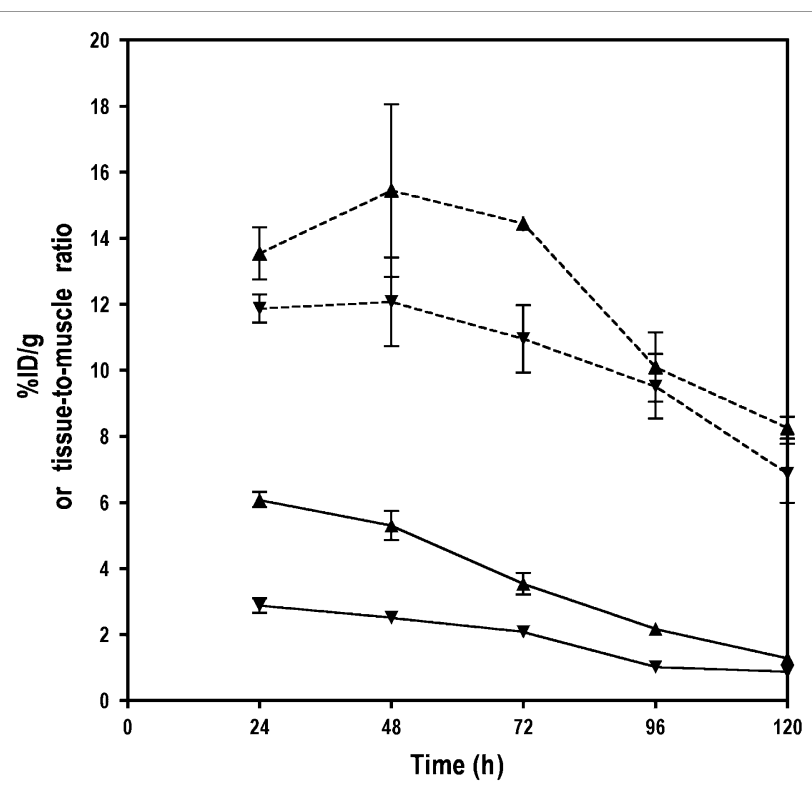

FIGURE 5. Time-activity curves for mAbs in U87 xenografts. Tumor time-activity curves (solid lines) and tumorto-muscle ratios (dashed lines) of either ${ }^{125} \mathrm{I}-12 \mathrm{G} 5(\boldsymbol{\Delta})$ or ${ }^{125} \mathrm{I}-\lg \mathrm{G}_{2 \mathrm{~A}}(\boldsymbol{\nabla})$ in U87 tumor-bearing severe combined immunodeficient mice. Data are mean \pm SEM of 3 animals. $\% \mathrm{ID} / \mathrm{g}=$ percentage of injected dose per gram of tissue.

simulating hypoxia demonstrated a considerable increase (5to 10-fold) in surface CXCR4 expression, which could account for the high uptake observed in the tumors. To confirm that the high radio-mAb uptake seen was not just because of changes in surface expression levels but because of an overall increase in protein expression, we also analyzed the total CXCR4 protein levels in U87 wild-type and tumorderived cells by immunoblot analysis. The immunoblot results demonstrated a considerable increase in total CXCR4 protein expression levels in both the hypoxia-induced U87 cells and the tumor-derived cell lines. Those observed CXCR4 expression levels indicate that the high ${ }^{125}$ I-12G5 uptake seen in larger tumors could, in part, be due to hypoxiainduced CXCR4 expression or tumor microenvironmentmediated clonal selection of highly CXCR4-expressing cells. Because of the extraction and passage of cells, the HIF$1 \alpha$ levels in the U87-TMD cells could not be assessed. On the other hand, elevated CXCR4 expression levels are known to persist even after 10 passages in culture, perhaps because of clonal selection (33). Even though there is evidence that HIF$1 \alpha$ upregulates CXCR4 expression in glioblastoma (34), it is not clear from our studies if the uptake observed is due to hypoxia or clonal selection.

Even though we used a subcutaneous brain xenograft model to demonstrate the principle, the observed results have translational potential to intracranial models. Because of a compromised blood-brain barrier, antibodies have been used as therapeutic and imaging agents for brain tumors and other lesions within the central nervous system (35-37). The imaging of CXCR4 expression may be particularly useful in the detection of infiltrative brain tumors that are known to have elevated CXCR4 expression levels (38). Those tumors are often not enhanced with standard MRI-based contrast agents, even though the tumors tend to be high-grade.

\section{CONCLUSION}

These results demonstrate the feasibility of the radioimmunoimaging of CXCR4 expression with an antihuman $\mathrm{mAb}$. Also, these results indicate the possibility of imaging tumor microenvironment-induced CXCR4 expression, thereby providing an indirect readout on the heterogeneity of tumors.

\section{ACKNOWLEDGMENTS}

We thank James Fox and Gilbert Green for assistance with imaging, Lee Blosser and Ada Tam for assistance with flow cytometry, and Dr. Catherine Foss for helpful discussions. This work was partially supported by grants from the National Cancer Institute (U24 CA92871) and the Education and Research Foundation of the Society of Nuclear Medicine.

\section{REFERENCES}

1. Wong D, Korz W. Translating an antagonist of chemokine receptor CXCR4: from bench to bedside. Clin Cancer Res. 2008;14:7975-7980.

2. Rempel SA, Dudas S, Ge S, Gutierrez JA. Identification and localization of the cytokine SDF1 and its receptor, CXC chemokine receptor 4, to regions of necrosis and angiogenesis in human glioblastoma. Clin Cancer Res. 2000;6:102-111.

3. Sehgal A, Keener C, Boynton AL, Warrick J, Murphy GP. CXCR-4, a chemokine receptor, is overexpressed in and required for proliferation of glioblastoma tumor cells. J Surg Oncol. 1998;69:99-104.

4. Rubin JB, Kung AL, Klein RS, et al. A small-molecule antagonist of CXCR4 inhibits intracranial growth of primary brain tumors. Proc Natl Acad Sci USA. 2003;100:13513-13518.

5. Redjal N, Chan JA, Segal RA, Kung AL. CXCR4 inhibition synergizes with cytotoxic chemotherapy in gliomas. Clin Cancer Res. 2006;12:6765-6771.

6. Berry DA, Cronin KA, Plevritis SK, et al. Effect of screening and adjuvant therapy on mortality from breast cancer. $N$ Engl J Med. 2005;353:1784-1792.

7. Lehman $C$, Schnall M. Imaging in breast cancer: magnetic resonance imaging. Breast Cancer Res. 2005;7:215-219.

8. Benard F, Turcotte E. Imaging in breast cancer: single-photon computed tomography and positron-emission tomography. Breast Cancer Res. 2005;7:153-162.

9. Kenny L, Coombes R, Vigushin D, Al-Nahhas A, Shousha S, Aboagye E. Imaging early changes in proliferation at 1 week post chemotherapy: a pilot study in breast cancer patients with $3^{\prime}$-deoxy- $3^{\prime}-\left[{ }^{18} \mathrm{~F}\right]$ fluorothymidine positron emission tomography. Eur J Nucl Med Mol Imaging. 2007;34:1339-1347.

10. Slamon DJ, Clark GM, Wong SG, Levin WJ, Ullrich A, McGuire WL. Human breast cancer: correlation of relapse and survival with amplification of the HER2/neu oncogene. Science. 1987;235:177-182.

11. Woo S, Bae J, Kim C, Lee J, Koo B. A significant correlation between nuclear CXCR4 expression and axillary lymph node metastasis in hormonal receptor negative breast cancer. Ann Surg Oncol. 2008;15:281-285.

12. Perik PJ, Lub-De Hooge MN, Gietema JA, et al. Indium-111-labeled trastuzumab scintigraphy in patients with human epidermal growth factor receptor 2-positive metastatic breast cancer. J Clin Oncol. 2006;24:2276-2282.

13. Linden HM, Stekhova SA, Link JM, et al. Quantitative fluoroestradiol positron emission tomography imaging predicts response to endocrine treatment in breast cancer. J Clin Oncol. 2006;24:2793-2799.

14. Mintun MA, Welch MJ, Siegel BA, et al. Breast cancer: PET imaging of estrogen receptors. Radiology. 1988;169:45-48.

15. Bian XW, Yang SX, Chen JH, et al. Preferential expression of chemokine receptor CXCR4 by highly malignant human gliomas and its association with poor patient survival. Neurosurgery. 2007;61:570-578. 
16. Kato M, Kitayama J, Kazama S, Nagawa H. Expression pattern of CXC chemokine receptor-4 is correlated with lymph node metastasis in human invasive ductal carcinoma. Breast Cancer Res. 2003;5:R144-R150.

17. Salvucci O, Bouchard A, Baccarelli A, et al. The role of CXCR4 receptor expression in breast cancer: a large tissue microarray study. Breast Cancer Res Treat. 2006;97:275-283.

18. Wu AM. Antibodies and antimatter: the resurgence of immuno-PET. J Nucl Med. 2009;50:2-5.

19. McKnight A, Wilkinson D, Simmons G, et al. Inhibition of human immunodeficiency virus fusion by a monoclonal antibody to a coreceptor (CXCR4) is both cell type and virus strain dependent. J Virol. 1997;71:1692-1696.

20. Lindmo T, Boven E, Cuttitta F, Fedorko J, Bunn PA Jr. Determination of the immunoreactive fraction of radiolabeled monoclonal antibodies by linear extrapolation to binding at infinite antigen excess. J Immunol Methods. 1984;72:77-89.

21. Schioppa T, Uranchimeg B, Saccani A, et al. Regulation of the chemokine receptor CXCR4 by hypoxia. J Exp Med. 2003;198:1391-1402.

22. Wachsberger P, Burd R, Dicker AP. Tumor response to ionizing radiation combined with antiangiogenesis or vascular targeting agents: exploring mechanisms of interaction. Clin Cancer Res. 2003;9:1957-1971.

23. Sun YX, Wang J, Shelburne CE, et al. Expression of CXCR4 and CXCL12 (SDF-1) in human prostate cancers (PCa) in vivo. J Cell Biochem. 2003;89:462-473.

24. Gupta SK, Pillarisetti K. Cutting edge: CXCR4-Lo-molecular cloning and functional expression of a novel human CXCR4 splice variant. J Immunol. 1999;163:2368-2372.

25. Hanaoka H, Mukai T, Tamamura H, et al. Development of a ${ }^{111} \mathrm{In}$-labeled peptide derivative targeting a chemokine receptor, CXCR4, for imaging tumors. Nucl Med Biol. 2006;33:489-494.

26. Baribaud F, Edwards TG, Sharron M, et al. Antigenically distinct conformations of CXCR4. J Virol. 2001;75:8957-8967.

27. Maeda H, Wu J, Sawa T, Matsumura Y, Hori K. Tumor vascular permeability and the EPR effect in macromolecular therapeutics: a review. J Control Release. 2000;65:271-284.

28. Beatty JD, Beatty BG, O'Conner-Tressel M, Do T, Paxton RJ. Mechanisms of tissue uptake and metabolism of radiolabeled antibody-role of antigen: antibody complex formation. Cancer Res. 1990;50(3, suppl):840s-845s.
29. Jones PL, Brown BA, Sands H. Uptake and metabolism of ${ }^{111}$ In-labeled monoclonal antibody B6.2 by the rat liver. Cancer Res. 1990;50(3, suppl):852s-856s.

30. Buchsbaum DJ, Wahl RL, Glenn SD, Normolle DP, Kaminski MS. Improved delivery of radiolabeled anti-B1 monoclonal antibody to Raji lymphoma xenografts by predosing with unlabeled anti-B1 monoclonal antibody. Cancer Res. 1992;52:637-642.

31. Beatty BG, O'Conner-Tressel M, Do T, Paxton RJ, Beatty JD. Mechanism of decreasing liver uptake of ${ }^{111} \mathrm{In}$-labeled anti-carcinoembryonic antigen monoclonal antibody by specific antibody pretreatment in tumor bearing mice. Cancer Res. 1990;50(3, suppl):846s-851s.

32. Carnec X, Quan L, Olson WC, Hazan U, Dragic T. Anti-CXCR4 monoclonal antibodies recognizing overlapping epitopes differ significantly in their ability to inhibit entry of human immunodeficiency virus type 1. J Virol. 2005;79:19301933.

33. Helbig G, Christopherson KW II, Bhat-Nakshatri P, et al. NF-кB promotes breast cancer cell migration and metastasis by inducing the expression of the chemokine receptor CXCR4. J Biol Chem. 2003;278:21631-21638.

34. Zagzag D, Lukyanov Y, Lan L, et al. Hypoxia-inducible factor 1 and VEGF upregulate CXCR4 in glioblastoma: implications for angiogenesis and glioma cell invasion. Lab Invest. 2006;86:1221-1232.

35. Kim KJ, Wang L, Su YC, et al. Systemic anti-hepatocyte growth factor monoclonal antibody therapy induces the regression of intracranial glioma xenografts. Clin Cancer Res. 2006;12:1292-1298.

36. Zalutsky MR, Moseley RP, Coakham HB, Coleman RE, Bigner DD. Pharmacokinetics and tumor localization of ${ }^{131}$ I-labeled anti-tenascin monoclonal antibody 81C6 in patients with gliomas and other intracranial malignancies. Cancer Res. 1989;49:2807-2813.

37. Takasu S, Takahashi T, Okamoto S, et al. Radioimmunoscintigraphy of intracranial glioma xenograft with a technetium-99m-labeled mouse monoclonal antibody specifically recognizing type III mutant epidermal growth factor receptor. J Neurooncol. 2003;63:247-256.

38. Ehtesham M, Winston JA, Kabos P, Thompson RC. CXCR4 expression mediates glioma cell invasiveness. Oncogene. 2006;25:2801-2806. 